\title{
A geometria no ensino fundamental: reflexões sobre uma experiência de formação envolvendo professores e alunos*
}

Saddo Ag Almouloud

Ana Lucia Manrique

Maria José Ferreira da Silva

Tânia Maria Mendonça Campos

Pontifícia Universidade Católica de São Paulo

Programa de Estudos Pós-Graduados em Educação Matemática

\section{Introdução}

Este artigo apresenta os principais resultados de um projeto de pesquisa financiado pela Fundação de Amparo à Pesquisa do Estado de São Paulo (FAPESP) e desenvolvido na Pontifícia Universidade Católica de São Paulo, tendo por objetivo investigar questões relacionadas à aprendizagem da geometria nas séries finais do ensino fundamental e reconhecer as representações dos professores dessas séries no que se refere ao papel da geometria no processo de formação do aluno.

Apesar de a geometria ser um ramo importante da Matemática, por servir principalmente de instrumento para outras áreas do conhecimento, professores do ensino fundamental apontam problemas relacionados tanto ao seu ensino quanto à sua aprendizagem.

* Outros membros da equipe de pesquisadores envolvidos no projeto: Nancy Cury Andraus Haruna, Rosana Nogueira de Lima, Vera Helena Giusti de Souza, Cileda de Queiroz e Silva Coutinho, Filomena Aparecida Gouvêa e Renata Rossini.
Talvez por isso solicitem, sempre que questionados a respeito do ensino de geometria, cursos de extensão que priorizem reflexões de suas práticas pedagógicas. Um diagnóstico dessa situação vem sendo discutido em meios acadêmicos e em instâncias governamentais. A Secretaria de Ensino Fundamental do Ministério da Educação (MEC), por meio dos Parâmetros Curriculares Nacionais (PCN) (Brasil, Ministério da Educação, 1998), aponta a necessidade de revisão dos modelos de formação de professores para a efetiva implantação de novas alternativas que complementam tais diagnósticos e provocam discussões a respeito do que, como e quando ensinar determinado conteúdo.

A avaliação educacional da rede estadual de São Paulo em 1998 - Sistema de Avaliação de Rendimento Escolar do Estado de São Paulo (SARESP, 2000) revela que muitos tópicos de matemática, pelo fato de não serem planejados ou ensinados pelos professores, não são aprendidos por seus alunos. Um exemplo disso é que, embora os professores indiquem a geometria como item importante, que merece lugar em todos os níveis de ensino, não há concordância quanto à seleção e à organização dos conteúdos a se- 
rem ensinados tanto no ensino fundamental como no ensino médio. Desta forma, não podemos esperar que os alunos construam uma pluralidade de conceitos geométricos a partir de conhecimentos ${ }^{1}$ obtidos por procedimentos experimentais, tal como recomendam os PCN.

Tais observações motivaram nossos questionamentos a respeito de problemas enfrentados quando do ensino e da aprendizagem da geometria nas séries finais do ensino fundamental. Nossa análise incidiu sobre os seguintes aspectos:

a) a origem de problemas relacionados ao ensino e à aprendizagem da geometria no sistema educativo e na formação dos professores;

b) as estratégias elaboradas pelo processo de formação para enfrentar pelo menos parte desses problemas;

c) as possibilidades de mudança nas concepções ${ }^{2}$ e nas práticas dos professores do ensino fundamental a partir de um processo de formação continuada.

Para o alcance desses objetivos adotamos os princípios da pesquisa-ação que proporcionam aos

1 Usamos os termos "saber" e "conhecimento" no sentido de Guy Brousseau (1998). Os conhecimentos são os meios transmissíveis (por imitação, iniciação, comunicação etc.) não necessariamente explicitáveis, meios de controle de uma situação para obter um resultado conforme as expectativas e as exigências sociais. Um saber é um conhecimento institucionalizado. A passagem do status de conhecimento ao status de saber implica transformações que os diferenciem; essas transformações são, em parte, justificadas pelas relações didáticas que se estabelecem na ocasião de um processo de ensino e de aprendizagem.

2 Entendemos o termo concepção como um ponto de vista local sobre um dado objeto matemático, caracterizado, de um lado, por sistemas de representações mentais, icônicas, simbólicas, e, por outro lado, por propriedades, invariantes, técnicas de tratamento, métodos específicos (implícitos ou explícitos) (Artigue, 1990). professores participantes do processo de formação a oportunidade de determinar suas condições de trabalho e de organizar comunidades formadas por profissionais da educação, dedicadas a promover experiências emancipatórias para os docentes e seus alunos (Kincheloe, 1997).

Esse processo de formação, segundo Thiollent (1998), deve ser concebido e realizado em estreita associação com ações e resoluções de problemas coletivos, nos quais os pesquisadores e os professores se envolvem de modo cooperativo ou participativo. O autor considera a pesquisa-ação como uma estratégia metodológica da pesquisa social na qual:

a) há uma ampla e explícita interação entre pesquisadores e pessoas implicadas na situação investigada;

b) desta interação resulta a ordem de prioridade dos problemas a serem pesquisados e das soluções a serem encaminhadas sob forma de ação concreta;

c) o objeto de investigação não é constituído pelas pessoas, e sim pela situação social e pelos problemas de diferentes naturezas encontrados nesta situação;

d) o objetivo da pesquisa-ação consiste em resolver ou, pelo menos, em explicitar os problemas da situação observada;

e) há, durante o processo, um acompanhamento das decisões, das ações e de toda a atividade intencional dos atores da situação;

f) a pesquisa não se limita a uma forma de ação (risco de ativismo): pretende-se aumentar o conhecimento dos pesquisadores e o conhecimento ou o "nível de consciência" das pessoas e grupos considerados. (p. 16)

Para a construção, a análise e a experimentação das situações de formação seguimos os princípios da Engenharia Didática (Artigue, 1988), que, vista como metodologia de pesquisa, caracteriza-se como um esquema experimental baseado em realizações didáti- 
cas em sala de aula. Compreendemos as realizações didáticas por concepção, realização, observação e análise de sessões de ensino.

$\mathrm{O}$ objetivo de integrar num mesmo projeto pesquisadores ${ }^{3}$ e professores do ensino fundamental ${ }^{4}$ não foi o de fornecer a esses professores uma espécie de "receita de como dar aulas", mas, sobretudo, o de despertar a atenção do grupo para a necessidade de um trabalho reflexivo sobre as ações pedagógicas, tendo como referência pesquisas sobre o ensino e a aprendizagem da matemática. Além disso, pretendíamos contribuir para a formação dos participantes, na expectativa de que se tornassem profissionais mais críticos, participativos e competentes para atuar em sala de aula e, portanto, mais do que executores de tarefas, procedimentos e técnicas.

Iniciamos o trabalho aplicando um questionário para diagnosticar concepções relativas tanto a conceitos geométricos quanto a posturas em sala de aula, o qual foi respondido individualmente pelos 24 professores de matemática participantes do processo de formação. O questionário foi organizado em cinco partes:

a) dados relativos à formação acadêmica;

b) perguntas relativas ao acesso a diferentes meios de informação;

c) a metodologia e a prática em que se apóia seu trabalho pedagógico;

d) sua opinião a respeito da importância do estudo da geometria, das dificuldades enfrentadas por seus alunos durante o processo de aprendizagem e das estratégias utilizadas para saná-las;

e) análise didática de erros dos alunos na resolução de problemas em geometria.

3 Professores da graduação, de pós-graduação e alunos de mestrado em Educação Matemática da PUC-SP.

4 Professores que atuam em escolas dos municípios de Guarulhos, de Caieiras, e da região central do município de São Paulo.
Paralelamente, foi aplicado um teste diagnóstico para alunos de $6^{\mathrm{a}}, 7^{\mathrm{a}}$ e $8^{\mathrm{a}}$ séries do ensino fundamental e da $1^{\text {a }}$ série do ensino médio das escolas da rede estadual em que esses professores lecionavam, a fim de verificar concepções de alunos a respeito de conceitos geométricos e de dificuldades que encontravam em relação a esses conceitos. As questões elaboradas a partir dos conteúdos de geometria do $3^{\circ} \mathrm{e}$ $4^{\circ}$ ciclos do ensino fundamental foram propostas para alunos da série subseqüente, de modo que um estudo prévio com conteúdos que poderiam ser trabalhados na $7^{\mathrm{a}}$ série foi realizado com alunos da $8^{\mathrm{a}}$ série para verificar se estes teriam domínio desses conhecimentos. Para a elaboração dessas questões foram consultados os Parâmetros Curriculares Nacionais de Matemática, a Proposta Curricular do Ensino Fundamental, os livros Experiências matemáticas da Secretaria de Estado da Educação de São Paulo e alguns livros didáticos. Assim, para a $7^{\mathrm{a}}$ série, foram selecionados os seguintes conteúdos: circunferência, triângulo retângulo, quadriláteros, Teorema de Tales e simetria axial. Para as demais séries, o processo foi análogo.

Aplicamos esse teste diagnóstico durante o primeiro semestre de 2000, e um segundo teste foi aplicado no final do mês de novembro de 2001, a fim de verificar possíveis alterações da prática do professor em relação ao ensino da geometria. Esse questionário foi analisado e confrontado com outras informações obtidas por outros instrumentos de nossa metodologia, como:

a) entrevistas com os professores objetivando discutir possíveis mudanças que estavam ocorrendo em suas concepções e práticas;

b) documentos escritos individualmente pelos professores em que comentavam fatos ocorridos nos encontros de formação e no seu contexto escolar;

c) mapas conceituais elaborados pelos professores para evidenciar inter-relações entre seus conhecimentos, suas concepções, suas emoções e seus sentimentos pesquisados em relação à geometria, ao seu ensino e à aprendizagem desta. 


\section{Procedimentos teórico-metodológicos empregados na formação de professores}

Com a identificação e a análise de algumas concepções de geometria dos professores participantes, desenvolvemos uma série de atividades, organizadas em encontros semanais de três horas cada, com o intuito de proporcionar condições favoráveis à reflexão sobre seu ensino e sua aprendizagem.

Elaboramos tarefas que permitissem ao professor rever seus conhecimentos sobre diferentes assuntos por meio da manipulação de materiais concretos, do uso de instrumentos de desenho e da construção de novos materiais. Como a atividade corporal, a manipulação de figuras e o desenho no quadro nem sempre possibilitam a visualização de noções geométricas, a formação envolveu o uso da linguagem Logo e do programa Cabri-géomètre II, considerando a importância do papel do computador e da geometria dinâmica para o ensino e aprendizagem da geometria.

Além disso, os professores tiveram oportunidade de elaborar, analisar e aplicar sequiências didáticas para o ensino de geometria em séries que lecionavam, com vistas a proporcionar aos seus alunos condições favoráveis à aprendizagem de conceitos e habilidades geométricas (construção, demonstração, raciocínio etc.), paralelamente a seus processos de formação.

Durante os anos de 2000 e 2001 e no primeiro semestre de 2002 tivemos 80 encontros, dos quais decorreu um total de 240 horas de observações registradas e analisadas pelo grupo de pesquisadores. Essas análises propiciaram correções e melhorias nas atividades, na dinâmica de formação e nas escolhas didáticas e metodológicas do projeto de pesquisa.

As atividades foram elaboradas segundo os princípios da Teoria das Situações (Brousseau, 1986) e os estudos dos registros de representações semióticas (Duval, 1995). Buscamos propor situações que permitissem ao professor em formação adquirir novos conhecimentos agindo, se expressando, refletindo e evoluindo por iniciativa própria. $\mathrm{O}$ formador, neste tipo de situação, tem o papel de mediador e de orientador, intervindo de maneira a deixar a construção do conhecimento sob responsabilidade do próprio professor.

Seguindo os princípios da Teoria das Situações (Brousseau, 1986), as atividades foram estruturadas de forma a comportar as fases de ação, formulação e validação, bem como a devolução e a institucionalização.

A fase de ação consiste em colocar o aluno frente a uma situação de ação em que, para solucionar o problema dado de forma mais adequada, haja necessidade do conhecimento que se pretende ensinar. Um verdadeiro diálogo deve instaurar-se entre a criança que age e a situação que lhe dá informações para sua ação. Esta dialética permite ao aluno criar um modelo implícito, o qual não necessariamente lhe permite formular ou organizar em teoria os resultados de seu comportamento.

O objetivo da fase de formulação é a troca de informações, momento em que o aluno ou grupo de alunos explicita as ferramentas utilizadas e a solução encontrada. Para que o aluno explicite seu modelo e para que essa formulação tenha sentido para ele, é necessário que outro(s) aluno(s) obtenha(m) os mesmos resultados. Essa troca de informações permitirá criar um modelo explícito, que poderá ser formulado com a ajuda de sinais e regras comuns, novas ou já conhecidas.

Enquanto o objetivo principal da situação de formulação é a comunicação lingüística, o da fase de validação é o debate sobre a veracidade das asserções e, como consequiência, as interações com o meio são organizadas. Como a validação empírica obtida nas fases precedentes é insuficiente no processo, o aluno deve mostrar por que o modelo que criou é válido. Para que ele mesmo construa uma demonstração que faça sentido para ele, é necessário que a faça em uma situação de validação, isto é, ele deve convencer alguém da validade de seus argumentos. Assim, a teoria funciona em debates científicos ou discussões entre alunos como meio de estabelecer provas ou rejeitá-las.

Uma vez construído e validado, o novo conhecimento fará parte do patrimônio da classe, embora ainda não tenha o status de saber social porque faltam as situações de institucionalização, em que o professor 
fixará convencionalmente e explicitamente o status cognitivo do saber. Se feita muito cedo, a institucionalização interrompe a construção do sentido, impedindo uma aprendizagem adequada e produzindo muitas dificuldades para o professor e para os alunos. Se for feita muito tarde, reforça interpretações errôneas e dificulta a aprendizagem e aplicações.

Esse processo de ensino e aprendizagem apóiase, principalmente, na noção de "devolução", definida como o ato pelo qual o professor faz o aluno aceitar a responsabilidade de uma situação de aprendizagem ou da resolução de um problema aceitando as conseqüências dessa responsabilidade.

As atividades foram elaboradas considerando também o estudo dos registros de representações semióticas desenvolvido por Duval (1995), segundo o qual a geometria envolve três formas de processo cognitivo que preenchem específicas funções epistemológicas:

a) visualização: exploração heurística de uma situação complexa, seja por uma simples observação ou por uma verificação subjetiva;

b) construção: processo por instrumentos de configurações que podem ser trabalhadas como um modelo, no qual ações e resultados observados são ligados aos objetos matemáticos representados;

c) raciocínio: processo do discurso para a prova e a explicação.

Ainda segundo Duval, esses três tipos de processos cognitivos estão entrelaçados em sua sinergia, sendo esta inter-relação cognitivamente necessária para a proficiência em geometria. Por outro lado, a heurística dos problemas de geometria refere-se a um registro espacial que dá lugar às formas de interpretações autônomas.

Como as escolhas teóricas e metodológicas foram realizadas visando a modificações de práticas docentes, enfatizamos a coordenação de diferentes registros de representação (a escrita algébrica, as figuras geométricas e o discurso na língua natural), preten- dendo que as figuras fornecessem um suporte intuitivo importante na resolução de um problema de geometria, de modo que ampliassem a possibilidade de percepção dos elementos do problema proposto, e ainda permitissem explorar esses elementos, antecipando e conjeturando. Privilegiamos a leitura e a interpretação de definições e propriedades matemáticas por entendermos que a compreensão de seu sentido global deve capacitar o professor a selecionar informações pertinentes, identificar e explicitar relações entre elas. Assim, nosso objetivo foi a constituição de uma rede semântica dos objetos matemáticos e dos teoremas solicitados por uma demonstração associada ao registro de representação em uma rede de propriedades lógicas.

Cada atividade foi aplicada no sentido de provocar nos professores a necessidade de mobilizar saberes já adquiridos, utilizando-os como ferramentas explícitas para resolver pelo menos uma parte do problema; e além disso, para provocar um debate pela confrontação dos resultados obtidos pelos professores, com o objetivo não somente de homogeneizar a constituição do saber coletivo do grupo, mas também promover o progresso na construção individual de conhecimentos.

Nessas ações de formação ficou patente a importância de o formador selecionar e organizar os novos conhecimentos e saberes dos professores, sistematizando-os para uma melhor compreensão do conceito visado. Essa fase, no decorrer do trabalho, foi chamada de institucionalização. Uma outra fase indispensável foi a de familiarização, na qual foram propostas situações-problema a serem resolvidas individualmente para consolidar os novos conhecimentos, o que, por sua vez, propicia ao formador perceber o desempenho de cada professor perante o novo conhecimento.

\section{Principais resultados da pesquisa}

\section{Origem de problemas e estratégias utilizadas}

Apontamos, a seguir, alguns aspectos que provocam dificuldades no processo de ensino e de apren- 
dizagem da geometria nas séries finais do ensino fundamental.

A análise do sistema educativo, do discurso dos professores e dos jogos que envolvem a própria geometria nos permite identificar certos fatores que podem ser considerados origem de dificuldades que os professores encontram no processo de ensino e de aprendizagem de saberes e de conhecimentos geométricos.

Em primeiro lugar, identificamos como fator de dificuldades o nosso sistema educativo, que define a política da educação com recomendações e orientações gerais sobre os métodos, os conteúdos e o saberfazer, deixando para cada escola definir os conteúdos que julga importantes para a formação de seus alunos, o que faz com que a geometria seja freqüentemente esquecida.

Podemos apontar, em relação à formação dos professores, que esta é muito precária quando se trata de geometria, pois os cursos de formação inicial não contribuem para que façam uma reflexão mais profunda a respeito do ensino e da aprendizagem dessa área da matemática. Por sua vez, a formação continuada não atende ainda aos objetivos esperados em relação à geometria. Assim, a maioria dos professores do ensino fundamental e do ensino médio não está preparada para trabalhar segundo as recomendações e orientações didáticas e pedagógicas dos PCN.

Além disso, alguns livros didáticos também contribuem para a origem de vários problemas, pois as situações de ensino apresentadas naqueles que analisamos e que são propostas para os alunos, de maneira geral, pela maioria dos professores, não enfatizam suficientemente a coordenação de registros de representação semiótica e a importância da figura para a visualização e exploração. Os problemas geométricos propostos por esses livros privilegiam resoluções algébricas, e poucos exigem raciocínio dedutivo ou demonstração. E ainda, quase não existe a passagem da geometria empírica para a geometria dedutiva, além de poucos trabalhos focarem a leitura e a interpretação de textos matemáticos. Essas abordagens criam no aluno concepções inadequadas no que diz respeito ao aprimoramento dos conceitos geométricos.
Para minimizar as dificuldades que os alunos enfrentam na compreensão desses conceitos, é imprescindível integrar no processo de ensino e de aprendizagem os seguintes tipos de apreensões identificados por Duval (1995):

a) seqüencial: é solicitada nas tarefas de construção ou nas de descrição com objetivo de reproduzir uma figura;

b) perceptiva: é a interpretação das formas da figura em uma situação geométrica;

c) discursiva: é a interpretação dos elementos da figura geométrica, privilegiando a articulação dos enunciados através da imersão dos mesmos numa rede semântica de propriedades do objeto;

d) operatória: é uma apreensão centrada nas modificações possíveis de uma figura e na reorganização perceptiva que essas modificações sugerem.

A resolução de problemas de geometria e a utilização do tipo de raciocínio que essa resolução exige dependem da distinção das formas de apreensão da figura. As modificações possíveis de uma figura pela apreensão operatória são classificadas por Duval do seguinte modo:

a) modificação "mereológica": a figura pode decompor-se em subfiguras, fracionando-se e reagrupando-se convenientemente segundo uma relação parte-todo;

b) modificação ótica: é a transformação de uma figura em outra, que será denominada "imagem";

c) modificação posicional: é o deslocamento da figura em relação a um referencial.

Essas modificações são realizadas graficamente e/ou mentalmente. O interesse de fracionar uma figura ou de examiná-la a partir de partes elementares está ligado à operação de re-configuração intermediária. Essa operação consiste em organizar uma ou várias 
subfiguras diferentes de uma figura dada, formando uma outra figura. Com efeito, as partes elementares obtidas por fracionamento podem ser reagrupadas em muitas subfiguras, todas dentro da figura de origem. Nessa operação podemos, por exemplo, realizar tratamentos como a obtenção de medidas de áreas por soma das medidas das áreas de partes elementares, ou ainda evidenciar a equivalência de dois reagrupamentos intermediários.

O processo de formação desenvolvido em nossa pesquisa considerou três aspectos. O primeiro foi trabalhar saberes, competências e habilidades em geometria para a formação dos professores, partindo da hipótese de que tal tipo de formação lhes permitiria, pelo menos parcialmente, a apropriação de certos saberes e conhecimentos geométricos. Segundo Mello, "ninguém facilita o desenvolvimento daquilo que não teve oportunidade de desenvolver em si mesmo. Ninguém promove a aprendizagem de conteúdos que não domina nem a constituição de significados que não possui ou a autonomia que não teve oportunidade de construir" (2002, p. 8-9).

O segundo foi fazer um trabalho de formação integrando resultados de pesquisas em educação matemática, visando a elaboração de instrumentos de análise de situações didáticas que poderiam, no futuro, ser desenvolvidas por esses professores em suas sala de aula. Nossas observações confirmaram os resultados de alguns pesquisadores da área quando mostram que, em geral, os professores possuem um discurso que integra resultados de pesquisas sobre o ensino e a aprendizagem da matemática que nem sempre é compatível com sua prática, uma vez que eles têm muitas dificuldades em operacionalizar essas idéias na construção, na análise e na experimentação de situações de sala de aula.

Finalmente, o terceiro foi estudar as práticas docentes e propiciar uma análise reflexiva e construtiva dessas práticas pelos próprios professores. Essa análise foi feita a partir do processo de construção de conhecimentos geométricos propostos pelas seqüências de ensino desenvolvidas em sala de aula, levando em conta aspectos epistemológicos e cognitivos (Robert,
2001, p. 65). Empregamos as expressões "práticas docentes" e "práticas em classe" segundo esta autora:

Reservamos a expressão práticas docentes ao conjunto das atividades do professor que norteiam suas praticas pedagógicas em sala de aula. As práticas em classe designam tudo o que o professor fala e faz em classe, levando em consideração sua preparação, suas concepções e conhecimentos em Matemática, e suas decisões instantâneas, se elas são conscientes. (idem, p. 66)

A seguir, apresentamos uma análise do estudo realizado sobre distância, ${ }^{5}$ essencial para o ensino da geometria, que aponta alguns fatores diretamente ligados à formação desse conceito. No decorrer do trabalho percebemos que os professores pesquisados preferiam e reivindicavam um trabalho voltado para a geometria métrica, alegando ser um conteúdo necessário para sua prática de sala de aula e com utilização no cotidiano. Pudemos observar que esses professores, pela sua dificuldade em abstrair, trabalhavam com maior facilidade na construção de relações a partir de observações de dados numéricos do que de figuras e configurações que não apresentavam esse tipo de dados, particularmente problemas relativos ao conceito de distância.

A dificuldade em fazer relações provavelmente é o que faz com que os professores tratem muitos dos conceitos (tais como o de distância) pelo senso comum, e não como um conteúdo matemático, mesmo que "aparentemente" reconheçam a distinção entre o que é do cotidiano e o que é da matemática. Embora o conceito de distância faça parte do currículo e possa ser trabalhado a partir das séries iniciais do ensino fundamental, percebemos que as dificuldades identificadas nestes professores se originam pela existência de concepções não estáveis sobre linha reta, perpendicularismo e altura, que interferem diretamente na construção do conceito de distância.

5 Uma análise mais aprofundada foi publicada em Manrique, Silva e Almouloud (2002). 
Percebemos que a formação anterior desses professores não parece ser suficiente para desenvolverem habilidades de compreensão de enunciados, de aquisição de vocabulário próprio e de análise de dados, o que impossibilita, em muitos casos, encontrar uma estratégia eficaz para a resolução do problema proposto.

Os professores parecem ter mais facilidade em lidar com situações concretas do que com situações que envolvem processos de abstração, o que dificulta a condução dos alunos a um pensamento mais genérico, mais formal ou mais abstrato. Além disso, demonstraram ter dificuldades em construir e analisar situações didáticas (Brousseau, 1986) que façam o aluno agir, expressar-se, refletir, evoluir por iniciativa própria, levando-o a adquirir novos conhecimentos. Nessas situações o professor tem o papel de mediador, de orientador, e suas intervenções deveriam ser feitas de modo que não se encarregue do trabalho essencial de construção de conhecimento. Nesta visão, a aplicação de cada atividade deveria contemplar as seguintes condições:

a) os alunos mobilizam os objetos conhecidos como ferramenta explícita para utilizarem um processo de resolução ou para resolverem, pelo menos, uma parte do problema;

b) o professor provoca um debate de confrontação dos resultados dos alunos, em que surgem várias formas de saber com o objetivo final de homogeneizar e constituir o saber da classe, além de promover o progresso na aquisição de conhecimentos; ou seja, dentro dos conhecimentos explicitados, o professor seleciona e organiza as descobertas dos alunos, fazendo assim uma sistematização dos conhecimentos e saberes novos envolvidos na atividade para uma compreensão do conceito visado.

A dificuldade encontrada pelos professores no desenvolvimento de tais situações está provavelmente relacionada, pelo menos em parte, ao modo como percebem e concebem o que é a matemática, o que é ensinar e aprender a matemática, modo esse desen- volvido por suas experiências e vivências enquanto alunos e profissionais.

\section{Mudanças em concepções e práticas}

O processo de formação tinha como um de seus objetivos retomar o espírito prático, experimental e científico de investigação nas escolas. Para isso, previa reflexões sobre ações e fenômenos educativos de modo a contribuir para o aperfeiçoamento da prática docente.

No que se refere às concepções e práticas pedagógicas, Manrique (2003) traz contribuições importantes que indicam possíveis mudanças com relação às concepções e à prática desses professores em relação à geometria e ao seu ensino.

Observamos que uma parte dos objetivos do processo de formação foi percebida e relatada por um dos professores.

Esta proposta traz em seu bojo a aceitação de que compreender significa mapear, romper fronteiras, buscar objetivos previamente traçados, valorizar a busca dos valores lógicos através de observações e contradições. Existe o incentivo à descoberta, à aposta na depuração do significado do conceito, na realização dos trabalhos em grupo. Produção significa vivenciar as situações propostas, apostar na evolução pessoal, descoberta e construção, valorizar conquistas localizadas, conhecer e aceitar o outro, seu ritmo e ideologias. (Professor A, Relatório 6, 27/7/2000)

O processo de mudança relatado por este professor inclui observações e contradições: observações para poder conhecer e agir; contradições surgidas dos confrontos com a realidade. A experiência nos permite perceber que o processo de mudança é pessoal e grupal, simultaneamente, uma vez que todos interferem nas mudanças de cada um, pois fazem parte da relação que ocorre em situações de aprendizagem. Assim, cada indivíduo tem seu próprio processo e ritmo. Como cada um tem seu tempo próprio para processar a mudança ocasionada por uma experiência.

Do ponto de vista do professor, visto como um 
indivíduo, mas sempre membro do grupo, as pequenas mudanças são percebidas em seus comentários, nos quais podemos identificar uma variável muito forte para que as grandes mudanças possam acontecer: a confiança. Confiar nos formadores, nas estratégias empregadas, nas outras pessoas do grupo e na própria capacidade de poder mudar. Uma outra variável apontada: as relações tecidas nas situações de aprendizagens. Charlot (2000) afirma que não existe saber sem a relação, e que esta não é só com o conteúdo a ser estudado. A relação de saber envolve relações com os outros elementos que estão presentes na ação educativa: os formadores tentam manter um controle e validar o saber; outros constroem o saber em conjunto com o formador e o partilham, necessitando que cada um enfrente diversos dilemas para que o saber possa ser adquirido (dilemas que são conseqüências naturais da própria história de vida e da formação de cada um); e a atividade proposta precisa estar coerente com as necessidades dos participantes e ser propícia para que o conteúdo possa ser explorado em suas diversas representações, gerando uma aprendizagem significativa.

A complexidade dos processos de mudança foi explicitada claramente no relatório desse professor que citamos anteriormente neste texto. Esse relatório foi elaborado após a aplicação da técnica dos mapas conceituais e a discussão dos diferentes mapas obtidos. Novak e Gowin (1999, p. 31) definem um mapa conceitual como "um recurso esquemático para representar um conjunto de significados conceituais incluídos numa estrutura de proposições”. Porém, os mapas conceituais foram usados como uma atividade criativa.

Nós utilizamos os mapas conceituais para que os professores pudessem estruturar palavras que viessem à mente relacionadas à palavra-chave dada a priori. Como os mapas conceituais são esquemas que as pessoas estruturam a partir de um conjunto de conceitos, não teremos obrigatoriamente duas pessoas elaborando um mesmo mapa quando se deparam com o mesmo conjunto de palavras. Apesar de a técnica dos mapas conceituais ser usada para estrutu- rar conceitos, explicitando relações e proposições entre esses conceitos, nós a utilizamos como uma atividade criativa. (Manrique, 2003, p. 40)

Essa maneira de utilizar os mapas conceituais permitiu que o professor tomasse consciência do seu processo de mudança e refletisse sobre os fatores que o estavam influenciando.

Pudemos também perceber algumas mudanças por meio das observações realizadas ao longo do tempo. Por exemplo, um dos professores mudou, a partir de um certo momento do trabalho, sua postura em relação ao erro cometido por outra pessoa. Em uma determinada atividade, esse professor fez uma descrição de um procedimento, e um outro, outra. Contrariamente ao que se passou em outras situações parecidas, ele não pediu para que o outro professor apagasse a sua descrição e nem apagou a sua, mas procurou entender o que o outro tinha feito e comparou com a sua própria produção. O problema proposto que permitiu essa tomada de consciência tinha um contexto especial, sua solução não era única, pois dependia do ponto de vista adotado pelo professor ao construir sua estratégia.

Em uma outra atividade pudemos perceber um outro tipo de mudança de comportamento. Na discussão dessa atividade, momento de socialização dos procedimentos e estratégias, a resolução de um dos professores foi apresentada aos outros, que fizeram diversas críticas e comentários. Chamou a atenção o fato de esse professor tentar justificar, explicar e defender sua descrição. Ele, desde o começo do processo de formação, apresentou dificuldades com os conteúdos matemáticos, com o uso do mouse, e insegurança na resolução dos exercícios. No momento de discussão, aceitou as correções somente após explicações e provas de que estava errado. Pudemos assim constatar a criação de um clima de liberdade de expressão, de abertura para que houvesse uma aprendizagem coletiva. Dessa forma, podemos inferir alguns atributos que precisam ser desenvolvidos para que ocorra a aprendizagem em grupo: tolerância 
para com a crítica à nossa produção; humildade para reconhecer que errou; paciência para com os outros; e vontade de ajudar o colega no sentido de não rebaixálo, e sim incentivá-lo a melhorar.

Um outro exemplo de mudança de postura vem da observação de uma atividade que consistia em construir um triângulo com varetas. No início dos encontros uma professora fazia o desenho sem se preocupar com as propriedades da figura representada por esse desenho. Em consequiência, suas construções não resistiam aos deslocamentos permitidos no ambiente de geometria dinâmica, o que lhe provocava uma grande frustração. Nessa atividade, o material concreto utilizado para a construção dos triângulos - varetas apresentava defeitos relacionados ao comprimento, o que lhe provocou dúvidas e necessidade de verificação da construção com régua e compasso. Ela se satisfazia sempre com a aparência das figuras! As atitudes de questionar, desconfiar, construir e provar são as que se espera de um professor e de qualquer aprendiz de matemática. O professor só pode facilitar e promover a aprendizagem de conteúdos que domina e para os quais construiu um significado.

Após um ano do processo de formação, realizamos uma entrevista com cada um dos professores participantes para que relatassem as possíveis mudanças ocorridas em sua prática. Alguns fatores foram apontados pelos professores como motivadores dos processos de mudança. Por exemplo, um professor relatou uma situação que ocorreu em um dos encontros e foi decisiva para que sua prática de sala de aula mudasse.

A formadora estava expondo outro dia, não sei se você se lembra, e falou: "Não, não, apaga o que eu falei, está tudo errado". Eu achei aquilo espetacular, achei fantástico. Ela falou: "Puxa, eu errei, vamos voltar e começar tudo outra vez". E eu falei: "Se ela faz, eu posso fazer, por que não?” Não é verdade? Isso é importante pra caramba. Eu achava que o professor era o dono da verdade, e não é. Porque, quando eu estudei, transmitiam isso para nós: "Eu sou o dono da verdade, eu sei tudo e acabou". E não é isso, a gente orienta. (Professor D, Entrevista, 27/3/2001)
O depoimento desse professor nos fala de suas crenças em relação ao "ser professor" e ao ensino da matemática, e de como essas crenças influenciam sua maneira de lecionar. Podemos assim perceber que, para que existam mudanças, torna-se necessário um investimento no processo de identificação das crenças do professor e uma orientação no sentido de sua percepção pelo próprio professor.

Para alguns professores, as diferentes dinâmicas utilizadas durante os encontros foram também fatores que influenciaram para a mudança individual, e mesmo coletiva. Citaram as dinâmicas nas quais os professores eram convidados a elaborar problemas e a discutir suas resoluções no grupo.

Cada um criar um problema, e depois analisar o que todos fizeram, o que cada um fez; essa dinâmica de se expor e ver o que você fez de errado, o que o outro fez... Isso eu achei interessante, achei que deu uma abertura legal. Você compara, às vezes você pensa que está fazendo uma coisa que todo mundo faz, ou que todo mundo trabalha do mesmo jeito, que ninguém tem problema com determinada coisa, só você, e aí você vê que todo mundo tem aquilo. É interessante essa troca de informações. Eu achei legal. (Professora E, Entrevista, 30/3/2001)

Essa professora fala da socialização de saberes, tanto de conteúdos matemáticos quanto do saber-fazer do dia-a-dia. Seu testemunho mostra que a tomada de consciência das diferenças individuais e da riqueza do trabalho no grupo fica, muitas vezes, adormecida, e que a troca de informações é necessária para que a prática pedagógica fique enriquecida. Essas trocas podem permitir que o professor se aproprie e analise sua realidade escolar e, conseqüentemente, possa fazer as intervenções necessárias para uma mudança da prática pedagógica.

Um outro professor, em sua entrevista, fala da importância da utilização das diversas linguagens matemática, natural e figural - no ensino da matemática (referência aos registros de representação semiótica de Duval, que adotamos como um dos quadros teóricos para este trabalho): 
A questão de perceber rapidamente, durante uma aula, o momento certo de você resumir com outros códigos, outros símbolos, uma idéia que está ali, passada, isso não é com uma faculdade que se percebe. Pelo menos não nos moldes da minha universidade, como a gente fez, puramente por observação, sem cobrança, por apresentação de idéias de nível geral, quase que utópico, com aluno perfeito. Agora, por outro lado, para acabar o problema é uma situação nova para nós que estamos tentando colocar em prática. Eu estava falando para os meus colegas que muitas vezes o curso de vocês, de três horas, serve para preparar aula para um mês, dois meses. E eu já tenho a idéia geral do que fazer em sala. Basta ter 10\% do "ferramental". (Professor A, Entrevista, 29/3/2001)

A integração coerente e precisa das linguagens é apontada como facilitadora do processo de ensinoaprendizagem, pois não é unicamente o domínio do conteúdo que permite ao professor dar uma boa aula e ao aluno aprender o conteúdo apresentado por este professor.

Nos mapas conceituais que esses professores construíram, as ações também tiveram sua representatividade. Palavras como manipulação, mexer, demonstração, visualizar, questionamento, observação, construção, abstração, iniciativa, representação e organização foram citadas por todos os professores. $\mathrm{O}$ estudo de tais mapas indica que esses professores perceberam quais seriam as ações necessárias para o ensino da geometria e que essas ações são representativas de uma parcela importante no processo de ensinoaprendizagem.

\section{Mudanças percebidas pelos alunos}

Essa fase da pesquisa teve por objetivo estudar as possíveis mudanças das práticas pedagógicas dos professores que participaram do processo de formação em geometria, segundo o ponto de vista de seus alunos, buscando verificar como os conteúdos foram trabalhados e apontando algumas das dificuldades que os alunos têm em resolver problemas de geometria.

Para a constituição do corpo de informações a ser analisado foi aplicado um questionário específico em uma sala de cada uma das séries finais do ensino fundamental de uma escola pública estadual da região central da capital de São Paulo. As salas escolhidas foram aquelas nas quais tinham sido desenvolvidas seqüências de ensino elaboradas pelos professores participantes do processo de formação.

O questionário, além de informações pessoais, pedia para resolver questões envolvendo geometria e solicitava que os alunos respondessem duas questões subjetivas, que permitiam fornecer uma visão de como o aluno tinha vivenciado a sequiência de ensino elaborada e aplicada pelo professor. As questões subjetivas foram as seguintes:

a) Neste ano seu professor de matemática desenvolveu alguma atividade diferente em sua sala de aula: relembre essas aulas, conte-nos o que aconteceu e dê sua opinião a respeito.

b) Escreva sobre suas aulas de matemática.

Apresentamos aqui somente um panorama das respostas fornecidas pelos alunos de $5^{\mathrm{a}}$ série, por serem representativas das outras séries em relação a essas questões, ressaltando aspectos didáticos, pedagógicos, matemáticos, contextuais e relacionais que julgamos relevantes e significativos. ${ }^{6}$

A turma da $5^{\text {a }}$ série escolhida para nossa análise era formada por 28 alunos, sendo 17 do sexo feminino e 11 do masculino, com idade variando entre 10 e 13 anos; 26 dos alunos estavam cursando a série pela primeira vez e todos relataram já terem estudado geometria. A seqüência de ensino trabalhada com esses alunos tratava de medidas de comprimento, procurando apresentar unidades diferentes das convencionais.

Mais da metade do número de alunos explicitou em seu discurso uma distinção entre as aulas de matemática e as das atividades de geometria, utilizando

6 Um estudo mais aprofundado pode ser obtido em Almouloud, Manrique e Gouvêa (2002). 
para isso termos trabalhados na seqüência de ensino: o pé, a jarda e a polegada como outras unidades de medida. Para exemplificar, segue a fala de um aluno:

$\mathrm{Na}$ aula de matemática tivemos uma aula diferente sobre geometria. Medimos a sala com os pés, falamos o que pode ser medido ou não, também medimos carteiras com algum padrão. O meu padrão foi o lápis. Medimos também com o barbante, o pé, o polegar. (A. 4)

Alguns alunos chamaram a atenção para o trabalho em grupo realizado nessas atividades, explicitando que aprenderam mais quando estavam em duplas:

Juntamos as carteiras entre dois alunos e aprendemos várias coisas. Eu achei muito legal, porque aprendi muitas coisas que me ajudaram muito. (A. 8)

Em relação à conscientização do processo de aprendizagem pelo próprio aluno, destacamos um dos relatos, explicitando que a aprendizagem de conteúdos matemáticos pode ser mais significativa:

Eu aprendi que o mar pode ser medido, que um prédio também etc. Eu gostei muito e minha opinião é que continuasse assim, porque nós aprenderíamos bem mais.

(A. 12)

Podemos dizer que a maioria dos alunos expressou satisfação e motivação pelas aulas de matemática, usando os seguintes termos para avaliá-las: "eu gosto", "são ótimas" e "são boas e interessantes". Alguns manifestaram a importância que a matemática possivelmente terá em suas vidas, por exemplo, vinculandoa ao futuro emprego:

[...] eu estudo matemática porque eu sei que vou precisar dela para crescer e ter um bom emprego. (A. 26)

Ao mostrar consciência sobre a importância da matemática para o desenvolvimento do indivíduo, alguns falaram que aprenderam assuntos diferentes e que as dificuldades encontradas requerem sempre um esforço pessoal, sinalizando que todos os alunos podem aprender a matemática, embora não citem aprendizagem:

\section{[...] cada dia aprendo uma coisa, às vezes é um pouco com- \\ plicado de entender, mas no final sempre aprendemos. Tem pessoas que têm um pouco de dificuldade, mas algum dia elas aprendem. (A. 8)}

Alguns alunos relataram um pouco do que acontece nas aulas de matemática, fornecendo uma visão da prática do professor em sala de aula. Outros falaram de aulas em sala de informática e de vídeo para quebrar a rotina e tornar as aulas mais interessantes:

\footnotetext{
[...] nas aulas de computação nós fazemos muitas coisas legais, ela dá jogos e traz CD-ROM para alguns dos alunos. Nós assistimos vídeos, ela traz fitas para os alunos assistirem e nós achamos legal... (A. 22)
}

Outra dinâmica utilizada pela professora relacionase à utilização do quadro-negro pelos próprios alunos. Alguns relataram que nesses momentos se sentiam constrangidos - os outros riam de seus erros -, embora para outros esses momentos tornavam a aula mais descontraída e divertida:

\section{[...] eu só não gosto quando a professora me chama para ir}

fazer conta na lousa. (A. 13)

[...] eu só não gosto de ir à lousa, pois se eu errar eu ficarei vermelha e todas(os) as(os) meninas(os) irão rir de mim.

(A.11)

Ela chama os alunos para irem à lousa, é super divertido.

Nós rimos bastante. (A. 14)

Apesar de a professora estar participando aproximadamente há dois anos do processo de formação em geometria, notamos certa insegurança para trabalhar com conteúdos desse campo em sua sala de aula. Além disso, alguns alunos relataram que uma outra professora, também participante do processo de formação e que tem a função de ser eventual para as 
ausências da professora, é quem ensina os conteúdos de geometria. Esse testemunho retrata, infelizmente, uma prática que sabemos existir em várias escolas: a dicotomização matemática/geometria, sendo que esta última, quase sempre, fica relegada no plano de curso dos professores titulares da classe para o final do ano; nesse caso, somente para as suas ausências.

[...] ela combinou com a professora de geometria para, nas aulas dela, usar a parte de geometria do livro de matemática. (A. 23)

As análises realizadas das questões subjetivas nos fornecem indícios de mudanças de prática pedagógica do professor e do interesse de seus alunos. O professor quer renovar suas estratégias de ensino desenvolvendo algumas das orientações metodológicas objetivadas pelo processo de formação em geometria aulas utilizando novas tecnologias, participação do aluno nas correções dos exercícios, explicitação do erro e sua utilização para identificar deficiências e possíveis dificuldades para a aprendizagem do aluno, leitura e cópia de livro para ajudar na aquisição da linguagem tanto corrente quanto matemática. Porém, o professor da sala analisada ainda apresentava, no momento da passagem desses questionários, receio de trabalhar com conteúdos da geometria, solicitando a uma professora eventual que desenvolvesse as unidades do livro que tratam desses conteúdos. Quanto aos alunos, notamos uma certa mudança em relação à crença usual de que a matemática só pode ser aprendida por alguns poucos alunos, pois relatam que, com algum esforço, eles conseguem aprender e que as aulas podem ser interessantes e "legais".

\section{Considerações finais}

Um dos pontos mais importantes de nossa pesquisa foi a elaboração dos procedimentos de investigação e de formação (questionários, entrevistas, estudo da origem dos problemas de ensino-aprendizagem, construção, análise didática e experimentação de situações de formação) que possibilitassem conhecer a predisposição dos professores frente à proposta, assim como tarefas que levassem professores e alunos à vivência e ao exercício do trabalho pedagógico, situando o uso do computador como uma possibilidade rica e promissora a ser explorada.

O conjunto das situações-problema proposto, que abrange quase todo o campo da geometria habitualmente trabalhada nas séries finais do ensino fundamental, foi escolhido de acordo com as preocupações dos professores. As situações justificam-se pelos quadros teóricos que escolhemos como pano de fundo: os registros de representação semiótica, a teoria das situações, os princípios da pesquisa-ação e da engenharia didática.

As ações desenvolvidas no processo de formação procuraram integrar as ações propostas pelos professores pesquisadores com as dos professores da rede pública de ensino. Nesses momentos de encontro, os professores em formação puderam descrever suas práticas, discuti-las e escolher as que caminham para uma proposta de integração mais formal e passível de um acompanhamento sistemático. A análise do discurso e das práticas docentes, assim como do discurso dos alunos sobre as ações pedagógicas vivenciadas, revela importantes indícios de mudanças nas concepções iniciais e nas práticas pedagógicas dos professores.

Mas os resultados encontrados nos revelaram outras questões, que nos permitem propor a continuidade da pesquisa. Pudemos perceber que, embora grande parte das atividades desenvolvidas envolvesse provas e demonstrações, os professores tiveram aproveitamento longe de nossas expectativas no que diz respeito à demonstração em geometria, sugerindo as seguintes questões: Quais fatores influenciam no processo de ensino e aprendizagem da demonstração? Quais ações desenvolver com os professores para lhes proporcionar uma apreensão significativa dos problemas, envolvendo provas e demonstrações? Quais fatores devem nortear a formação inicial e continuada dos professores no que diz respeito às provas e demonstrações em matemática, em especial em geometria? Outros pontos que merecem estudo referem-se às questões relacionadas à compreensão do trabalho 
do professor, suas lógicas de ação, o sistema de decisão que orienta sua ação e os fatores que interferem na formação de conceitos numéricos, algébricos e estocásticos - tanto dos professores quanto de seus alunos.

SADDO AG ALMOULOUD, doutor em educação matemática pela Universidade de Rennes I - França, é professor da Pontifícia Universidade Católica de São Paulo, atuando no Programa de Estudos Pós-Graduados em Educação Matemática. Publicou recentemente: Une réflexion sur l'enseignement et l'apprentissage de la géométrie au Brésil: análise du discours du maître. In: Actes de la 11eme École d'Été de Didactique des Mathématiques. (Grenoble: ARDEM, 2001, p. 1-19); ALMOULOUD, S. Ag, (2003). Registro de representação semiótica e compreensão de conceitos geométricos. In: MACHADO, Silvia Dias Alcantara (org.). Aprendizagem em matemática: registros de representação semiótica (Campinas: Papirus, 2003, p. 125-148). Projeto de pesquisa atual desenvolvido pelos autores: O pensamento matemático no ensino fundamental: formação de núcleos de ensino-aprendizagem e pesquisa. E-mail: saddoiag@ @ucsp.br

ANA LUCIA MANRIQUE, doutora em psicologia da educação pela Pontifícia Universidade Católica de São Paulo, é professora nessa universidade e na Universidade São Judas. Publicou recentemente: MANRIQUE, A. L., GOUVEA, F. A. T., ALMOULOUD, S. Ag Análise da prática pedagógica em geometria: o ponto de vista do aluno do ensino fundamental. Contrapontos. Itajaí, $\mathrm{n}^{\circ} 6$, set.-dez., p. 325-341, 2002. MANRIQUE, A. L., BIANCHINI, B. L., SILVA, B. A., SOUZA, V. H. G., DUBUS, M. T. G. Uma ruptura do Contrato Didático no estudo do comportamento de funções. Educação Matemática em revista. São Paulo, v. 11a, p. 7377, 2002; MANRIQUE, A. L. A afetividade manifestada por professores participantes de um processo de formação em geometria. In: 26 ${ }^{\mathrm{a}}$ Reunião Anual da ANPEd, 2003, Rio de Janeiro: ANPEd, 2003. v. 1, p. 1-20, CD-ROM. E-mail: manrique@pucsp.br

MARIA JOSÉ FERREIRA DA SILVA, doutoranda em educação matemática pela Pontifícia Universidade Católica de São Paulo, é professora nesta universidade. Publicou recentemente: SILVA, M. J. Ferreira da, ALMOUDOUD, S. Ag: Números fra- cionários: uma formalização das concepções de professores do ensino fundamental. In: VII Encontro Brasileiro de Estudantes de Pós-Graduação em Educação Matemática (EBRAPEM). PGEM UNESP/Rio Claro, 2003; SILVA, M. J. Ferreira da, MANRIQUE A. L., ALMOULOUD, S. Ag: Conceitos geométricos e formação de professor do ensino fundamental. 25 $5^{\text {a }}$ Reunião Anual da ANPEd. Disponível em: <http://www.anped.org.br>.E-mail: zeze@pucsp.br e mzefs@terra.com.br

TÂNIA MARIA MENDONÇA CAMPOS, doutora em matemática pela Universidade de Ciências e Tecnologia de Languedoc (USTL) (Montpellier, França), é professora da Pontifícia Universidade Católica de São Paulo. Publicou recentemente: CAMPOS, T. M. M., PIRES, C. M. C., CURI, E. Espaço e forma: a construção de noções geométricas pelas crianças das quatro séries iniciais do ensino fundamental (São Paulo: PROEM, 2001, v. 1, p. 286); CAMPOS, T. M. M., NUNES, T., MAGINA, S., BRYANT, P. Introdução à educação matemática: os números e as operações numéricas. (São Paulo: PROEM, 2001, v. 1, p. 176); CAMPOS, T. M. M., PIRES, C. M. C., CURI, E. Construindo propostas de trabalho para a área de ciências da natureza, matemática e suas tecnologias, juntamente com professores do ensino médio: o uso da educação à distância num projeto de formação continuada de professores. XI Conferência Interamericana de Educação Matemática, 2003, Blumenau, CD-ROM. E-mail: tania@pucsp.br

\section{Referências bibliográficas}

ALMOUlOUD, S. Ag, MANRIQUE, A. L., GOUVÊA, F. A. T., (2002). Análise da prática pedagógica em geometria: o ponto de vista do aluno do ensino fundamental. Contra Pontos, Revista de Educação da Universidade do Vale do Itajaí, ano 2, no 6, set.-dez., p. 325-341.

ARTIGUE, M., (1988). Ingénierie didactique. Recherches en Didactique des Mathématiques, Grenoble, v. 9, nº 3, p. 281308.

, (1990). Epistémologie et didactique. Recherches en Didactique des Mathématiques, Grenoble, v. 10, n 2-3, p. 241-286.

BRASIL, Ministério da Educação, (1998). Parâmetros Curriculares Nacionais: Ensino Fundamental - Matemática. Brasília: Secretaria de Ensino Fundamental. 
BROUSSEAU, G., (1986). Fondements et méthodes de la didactique des mathématiques. Recherches en Didactique des Mathématiques, Grenoble, v. 7, nº 2, p. 33-115.

, (1998). Théorie das situations didactiques. Textes rassemblés e preparés par Nicolas Balacheff, Martin Cooper, Rosamund Sutherlan, Virginia Warfield. Recherches en Didactique des Mathématiques. Grenoble: La Pensée Sauvage.

CHARLOT, B., (2000). Da relação com o saber: elementos para uma teoria. Porto Alegre: Artes Médicas Sul. Tradução de Bruno Magne.

DUVAL, R., (1995), Sémiosis et pensée humaine: registres sémiotiques et apprentissages intellectuels. Bern: Peter Lang.

KINCHELOE, J. L., (1997). A formação do professor como compromisso político: mapeando o pós-moderno. Porto Alegre: Artes Médicas.

MANRIQUE, A. L. (2003). Processo de formação de professores em geometria: mudanças em concepções e práticas. Tese de doutorado em Psicologia da Educação. Pontifícia Universidade Católica de São Paulo.

MANRIQUE, A. L., SILVA, M. J. F. da, ALMOULOUD, S. Ag, (2002). Conceitos geométricos e formação dos professores do ensino fundamental. Trabalho apresentado na $25^{\mathrm{a}}$ Reunião Anual da ANPEd. Disponível em: 〈http://www.anped.org.br> (GT19). Acesso em: 20 mar. 2003.

MELLO, G. N., (2002). Formação inicial de professores para educação básica: uma (re)visão radical. Disponível em: <http:// www.crmariocovas.sp.gov.br>. Acesso em: 15 mar. 2003.

NOVAK, J. D., GOWIN, D. B., (1999). Aprender a aprender. $2^{\mathrm{a}}$ ed. Portugal: Plátona Edições Técnicas. Tradução de Carla Valadares.

ROBERT, A., (2001). Les recherches sur les pratiques des enseignants et les contraintes de l'exercice du métier d'enseignant. Recherches en Didactique des Mathématiques, Grenoble, v. 21, no 1-2, p. 57-80.

SARESP, (2000). Avaliação de Rendimento Escolar do Estado de São Paulo 1998. São Paulo: Secretaria de Estado da Educação/Fundação para o Desenvolvimento da Educação.

THIOLLENT, M., (1998). Metodologia da pesquisa-ação. $8^{\text {a }}$ ed. São Paulo: Cortez.

Recebido em outubro de 2003 Aprovado em junho de 2004 
gulamentos que levaram à criação de um grupo de trabalho específico sobre educação matemática na ANPEd (Igliori).

Miguel e Garnica, por fim, discutem, sob referenciais distintos, a disciplinarização da educação matemática. São, em resumo, quatro olhares e vozes que, ora em fina sintonia, ora em contraponto, surgem fincados no espaço que os autores desejam, com seus discursos, ver consolidado: a educação matemática.

Palavras-chave: educação matemática; pesquisa; disciplinarização

Mathematical education: a brief history, actions adopted and questions on its formation as a discipline

This text was elaborated in autonomous topics in order to discuss the configuration of mathematical education as an area of research and, in a historical panorama, explains and analyses how the efforts for its consolidation in Brazil have been effectively implemented. Starting from a presentation of some elements related to the emergence and organisation of research in mathematical education within an international perspective (D'Ambrósio), it goes on to sketch in the motivations and difficulties which led to the creation of a specific working group in mathematical education within ANPEd (Igliori). Finally, Miguel and Garnica discuss the implementation of mathematical education as a discipline from different theoretical perspectives. There are, then, four different views and voices, at times finely tuned and, at others, discordant which arise rooted in that space which the authors with their discourses, desire to see consolidatedmathematical education.

Key-words: mathematical education; research; formation as a discipline

Saddo Ag Almouloud e outras

A geometria no ensino fundamental: reflexões sobre uma experiência de formação envolvendo professores e alunos

Discute os principais resultados de um projeto de pesquisa que teve como objetivo investigar problemas relativos ao ensino e à aprendizagem da Geometria, enfrentados por professores da rede pública estadual de ensino, bem como por seus alunos de $5^{\mathrm{a}}$ a $8^{\mathrm{a}}$ séries. Analisa essencialmente procedimentos metodológicos, fundamentos teóricos e principais resultados, focalizando a origem dos problemas relacionados com o ensino e a aprendizagem da Geometria, as estratégias montadas para enfrentar uma parte desses problemas e as mudanças de concepções e práticas de professores.

Palavras-chave: ensino e aprendizagem; geometria; formação de professores; mudança de práticas pedagógicas

The geometry in primary education: reflections on a training experience involving teachers and school children

In this text we present the main results of a research project whose aim was to investigate teaching and learning problems in Geometry, faced by public school teachers and their pupils from $5^{\text {th }}$ to $8^{\text {th }}$ grade. We intend to concentrate our discussion on methodological procedures, theoretical concepts and main results, focusing our analysis on three aspects: first, the origin of problems related to the teaching and learning of Geometry; second, the courses of action adopted to confront some of these problems; and third, changes in teachers' concepts and practices.

Key-words: teaching and learning; geometry; teacher development; changes in pedagogical practices

Maria Cecilia de Castello Branco Fantinato
A construção de saberes matemáticos entre jovens e adultos do Morro de São Carlos

O texto procura compreender as relações entre os conhecimentos matemáticos construídos por jovens e adultos trabalhadores na vida cotidiana e os conhecimentos matemáticos escolares. Para tanto, foi desenvolvida uma pesquisa etnográfica no Morro de São Carlos, Rio de Janeiro, acompanhando a rotina local de um curso de educação de jovens e adultos, assim como aspectos da vida diária dos alunos e da vida comunitária na favela. Os resultados indicaram uma estreita associação entre o uso de habilidades matemáticas no cotidiano com a necessidade de garantir formas de sobrevivência, assim como a importância de fatores afetivoemocionais como impulsionadores de raciocínio matemático. $\mathrm{O}$ mundo da escola e o mundo da vida cotidiana apareceram como separados, assim como os conhecimentos matemáticos pertencentes a um ou outro contexto. Palavras-chave: etnomatemática; educação matemática de jovens e adultos; representações quantitativas e espaciais

The construction of mathematical knowledge by young people and adults from Morro de São Carlos This study aimed to understand relationships between the everyday mathematical knowledge constructed by working-class youth and adults and the school mathematical knowledge that they confront when they return to school for basic education. For this study, an ethnographic research methodology was developed in a poor neighbourhood of the city of Rio de Janeiro, Morro de São Carlos, monitoring routines of a local course for adult education, as well as aspects of the daily life of the students and their community. Results showed a strong association between the use of mathematical skills in daily life and survival strategies to satisfy basic needs. Emotional factors appeared to stimulate some of the subjects' mathematical strategies. For 